\title{
APRESENTAÇÃO: CORPO E LITERATURA/BODY AND LITERATURE
}

\author{
Eliane Campello* \\ Universidade Federal do Rio Grande \\ Rio Grande, RS, BR \\ Universidade Católica de Pelotas \\ Pelotas, RS, BR
}

Rita Terezinha Schmidt ${ }^{* *}$

Universidade Federal do Rio Grande do Sul

Porto Alegre, RS, BR

O corpo é a matéria encarnada que nos constitui e que habitamos, a fronteira física que permite o reconhecimento de um existir no mundo enquanto experiência vivida de um eu singular, no contexto relacional com o(s) outro(s) corpo(s)-não eu. Tal concepção - de um corpo perceptivo que estabelece um elo entre morfologia e um campo de intencionalidades e afetos - remonta ao pensamento do filósofo Edmund Husserl em seu Ideias para uma fenomenología pura, de 1913), posteriormente expandido por seu seguidor Merleu-Ponty em seus estudos sobre o corpo físico e o corpo vivido, particularmente em seu A fenomenología da percepção, publicada em 1945. Não há dúvidas de que a fenomenología abriu o caminho para novas possibilidades de compreensão sobre o corpo na sua interrelação com a mente bem como sobre a constituição do sujeito da percepção e do comportamento, da cognição, da reflexão, dos afetos e da criatividade. Pode-se dizer que o século XX foi um período fértil de renovação e inovação de reflexões sobre o corpo durante o qual o pensamento ocidental empreendeu a superação do sistema de oposições que, ao lon- go de séculos, definiu o corpo como um dado biológico previamente constituído, relegado à esfera da imanência, uma composição biofísica opaca e irredutível tida como um obstáculo à objetividade, princípio da moldura conceitual da busca do conhecimento 'verdadeiro' sobre a natureza e a natureza humana.

A constância do dualismo matéria/subtância figura no Crátilo de Platão, onde o filósofo coloca em discussão a doutrina das formas e concebe a matéria como uma versão degradada e imperfeita da Ideia, portanto uma fonte de interferência que punha em risco as operações da razão. Platão reconhece o legado dos sacerdotes órficos que introduziram o termo corpo (soma) na concepção do humano como um ser espiritual e incorpóreo contido em uma prisão (sema). Nesse contexto, o corpo aprisionado representa uma traição à alma e à razão. Aristóteles, por sua vez, se alinha a essa tradição na explicação da chora, no Timeus, onde ratifica a ontologia do corpo como materialidade, um corpo assujeitado às leis da physis cujo ímpeto deveria ser regulado e controlado em nome da harmonia do estado. Na tradição cristã da

\footnotetext{
* Eliane Campello possui graduação em Curso de Ciências Jurídicas e Sociais pela Fundação Universidade Federal do Rio Grande (1972), graduação em Curso de Letras Português Inglês pela Fundação Universidade Federal do Rio Grande (1977), mestrado em Letras Literatura Anglo Americana pela Universidade Federal do Rio Grande do Sul (1992) e doutorado em Letras Literatura Comparada pela Universidade Federal do Rio Grande do Sul (2000). Atualmente é professora colaboradora da Universidade Federal do Rio Grande (FURG) e professora da Universidade Católica de Pelotas (UCPeL).

${ }^{* *}$ Rita Terezinha Schmidt possui graduação em Letras pela Universidade Federal do Rio Grande do Sul (1974), M.A. (1978) e PhD (1983) pela University of Pittsburgh, EUA. Desde 1994 é professora titular da Universidade Federal do Rio Grande do Sul, Departamento de Línguas Modernas. É bolsista de produtividade $1 \mathrm{~B}$ do $\mathrm{CNPp}$.Atua nas áreas de literaturas de língua inglesa, literatura comparada e teoria da literatura, com ênfase nos seguintes tópicos: teorias feministas e teorias pós-coloniais, estudos interdisciplinares de gênero, resgate de escritoras brasileiras e crítica da cultura.
} 
Idade Média, o dualismo matéria e forma (substância) é reconfigurado na visão da alma divina e do corpo como carnalidade pecaminosa. Na teologia antropológica e racionalista de Santo Agostinho, particularmente na obra Cidade de Deus (século XV), há uma batalha constante sobre o dualismo alma imortal/corpo mortal, cuja relação harmoniosa teria sido rompida com a queda do Paraíso. Na sua incorporação do neoplatonismo, Santo Agostinho preconizava a iluminação interior (graça) como uma dotação divina, mas ela só estaria presente e manifesta nas mentes racionais.

A formulação moderna do pensamento cartesiano no século XVII não constitui uma ruptura, propriamente dita, com a ontología dualista que vigorava até então. Em certo sentido é uma síntese do pensamento anterior, muito embora o trabalho investigativo de René Descartes fosse orientado por uma metodologia específica que lhe conferiu o estatuto de pai fundador da medicina científica moderna. Um dos objetivos de seu As meditações metafísicas (1641) foi o de encontrar provas para a crença de que a alma humana sobrevive à morte do corpo, de maneira que o corpo morto desempenha um papel metodológico significativo em suas pesquisas, o que explica os anos em que passou dissecando e desmembrando animais mortos. Para Susan Bordo em seu The flight to objectivity (1987) muito do referido texto pode ser lido como uma prescrição de regras para a liberação da mente das várias seduções do corpo. A dissecação de corpos mortos como instrumento primário de conhecimento levou Descartes a argumentar que a vitalidade se origina nos processos mecânicos do corpo - a animação - cujo modelo deriva do funcionamento de máquinas inanimadas. Descartes era obcecado pela noção da natureza do autômato, tanto é que substituiu a visão da natureza aristotélica dotada de uma mágica natural com suas simpatias e humores pela noção de natureza definida como res extensa, matéria passiva impulsionada por forças mecânicas em cujo modelo o corpo humano é considerado como res extensa, dissociado da mente incorpórea, ou res cogitans. Impulsionada pelo desejo de controle e posse da natureza, que fica explícito em partes do Discurso do método (1637), a ontologia cartesiana separou, de forma decisiva, as esferas da cultura e da natureza, da mente e do corpo, da razão e da emoção. Trata-se da concepção de um mundo morto, onde não há espaço para subjetividade e intencionalidade.

Reconfigurações e transformações de heranças seculares sobre o corpo ocorreram no século XIX, através de dois pensadores para quem o corpo vivido constitui uma estrutura própria que não pode ser entendida pelo conceito de natureza inanimada. Friedrich Nietzsche em Para além do bem e do mal (1886) rejeita modelos centralizadores da mente e afirma que a mente não é uma única substância da qual as idéias seriam sua manifestação, mas sim um ecossistema relacional e unificado de idéias. Ao conceber a interação entre corpo e mente, postulou a compreensão do corpo como uma estrutura social, composto de muitas almas (no sentido de personae). Cabe destacar o fato de Nietzsche ter negado a existência de um Eu ou ego por trás da frase 'Eu penso', prefigurando assim o que viria a ser a corrente do construtivismo linguístico do século XX. Com a psicanálise freudiana, emerge o corpo sexualizado, no entrecruzamento do biológico com uma descrição quase fenomenológica do corpo, com seus instintos primitivos e pulsões da libido (uma versão do Eros) que praticamente reduz o corpo a uma zona de luta entre desejos, objetos e a lei do pai. Contudo, no clássico texto de 1905, "Três ensaios sobre a teoria da sexualidade", há uma mudança significativa em sua compreensão do corpo em relação à vida psíquica na medida em que realinha a compulsão do desejo com uma necessidade instintiva de afeto, um requisito da noção de confiança, associada ao amor sexual. Dessa forma, Freud sinaliza um diálogo entre o nível da necessidade fisiológica e o nível da necessidade psicológica o que, num certo sentido, significa afirmar que natureza e cultura coexistem no corpo vivido.

Ao longo da história, o corpo foi colonizado pelas práticas discursivas da filosofia e das ciências naturais e sociais, campos minados por pressupostos sobre sua natureza, seu estado bruto como um já-dado, imutável, inerte e passivo, sua constituição biológica e pré-cultural e sua imunidade aos fatores históricos, sociais e culturais. De qualquer forma, até recentemente, o corpo foi pensado, predominantemente, de acordo com valores sociais, morais e religiosos, e particularmente, em termos da constituição binária de dois sexos, o masculino 
e o feminino. Repensar o corpo em sua materialidade e subjetividade implicou deslocamentos e rupturas epistemológicas significativas e esse feito coube aos pensadores do século XX, entre os quais Michel Foucault, que no três primeiro volume da História da sexualidade (1976/1984) denunciou as funções de normalização da psicanálise e questionou a realidade material de corpos anatomicamente distintos a partir do dispositivo da sexualidade. Para Foucault, o corpo não pode ser adequadamente compreendido como entidade natural, précultural ou ahistórica uma vez que não é tão somente inscrito e marcado por pressões e valores sociais, mas se torna produto, ou seja, efeito direto da própria construção do campo social e de seus discursos. Isso pressupõe compreender que a naturalidade do corpo é construída por efeitos de manobras discursivas que transformam a sua materialidade em linguagem e em efeito de poderes. Nesse sentido, o corpo não tem mais um estatuto ontológico fora dos atos que constituem sua realidade. Todavia, dizer que a realidade humana só pode ser compreendida pela mediação da linguagem não implica negar a concretude do corpo como realidade vivida como carnalidade. É levando em consideração essa condição que Elizabeth Grosz em Volatile bodies (1994) define o corpo como imanente e transcendente. Se, por um lado, o corpo nem sempre acata completamente as normas que impõem ou disciplinam sua materialização, o que justamente possibilita linhas de fuga e abertura para a subversão da identidade no contexto de processos de socialização, por outro, o corpo impõe que o sujeito seja um ser para o mundo, pois é ele que possibilita a visão e a dimensão de espaço onde se vive.

Discursos e representações do corpo podem ser considerados sintomas de processos de transformação histórica, pois é neles que se inscrevem a relação subjetividade/objetividade bem como processos de submissão ou de resistência à opressão e à dominação. Por isso, imagens do corpo constituem uma lente para a análise dos movimentos da história, da cultura e da literatura. A literatura, particularmente, sempre foi um campo simbólico habitado por representações do corpo, indissociadas de estruturas de referencialidade, seja em termos de repetibilidade (imitação) ou de subversão. Mas é a partir do século XVIII que a literatura é territoriali- zada por discursos e representações do corpo, de forma que Terry Eagleton, ao examinar as condições histórico-políticas que favoreceram o surgimento da estética e seu papel dominante no pensamento moderno, afirma em seu A ideologia da estética (1990) que a estética ganhou autonomia em razão de tornar-se o protótipo da subjetividade, com destaque para o significado e as intensidades do corpo no campo da produção cultural.

A equação metafórica "o corpo escrito/a escrita do corpo" parece dominar as associações feitas por filósofos e teóricos que analisam a relação entre o corpo e a literatura. Em O lugar do corpo na cultura ocidental (1999), Florence Braunstein e Jean-François Pépin afirmam que a partir das representações do corpo na literatura grega "irrompe a maneira como a sociedade considera o corpo" (40). Nós, hoje, no século XXI, somos as/os herdeiras/os culturais dos gregos, porquanto nos conscientizamos de que o corpo "pode ser simbolizado como o ponto de apoio desse eixo da reflexão que liga, simultaneamente, o passado e o futuro, o profano e o sagrado" (14). O corpo vai muito além dos elementos biológicos, pois é também e, principalmente, o catalisador essencial de fatos, ações e (re)criações no âmbito social, psicológico, estético, cultural, religioso, entre outros.

O corpo conserva-se no centro de toda a literatura universal. Braunstein e Pépin se perguntam e nos perguntam: "Que relação pode existir entre o problema do corpo e os gêneros literários?". Encarregam-se também da resposta: "Tanto um como os outros correspondem a atitudes, a comportamentos, revelando as relações de uma sociedade com o seu corpo" (s./d., 53). As transformações culturais, políticas e econômicas da sociedade trazem como consequência a escolha de novos temas a serem tratados na literatura (no romance, em particular), como a conformação física das cidades, o movimento entre as classes sociais com a subida do operariado, os movimentos de contracultura com o feminismo. O comportamento social representado na literatura é refratado no corpo, lugar em que são percebidas estas mudanças por meio dos simbolismos e dos conceitos filosóficos, bem como das correntes científicas que passam de um a outro século.

Por meio do corpo na literatura é possível tratar de problemas relativos à liberdade, à ética, à estética, 
à sexualidade, à medicina, ao direito. No decorrer da história, o corpo tornou-se múltiplo, tal como ocorreu com a diferenciação que atingiu as variadas esferas do conhecimento. Além e apesar de o corpo ser o lugar da memória individual e da coletiva, que se transmite de uma geração à outra, "No existe la corporeidad abstracta. El cuerpo [na literatura] es por excelencia el lugar de la intersección de las dominaciones de clase, de género y de 'raza'; en él se fomentan igualmente diversas tácticas de resistência" (HABER, 2007, 5).

Atualmente, sem dúvida, o corpo constitui um elemento relevante para apreender e compreender a cultura e a literatura, a partir de perspectivas multi/ inter/disciplinares. O corpo, considerando-se especialmente o imaginário feminino, como o faz Elódia Xavier em Que corpo é esse? (2007), pode levar a análises sob inúmeros aspectos, conforme se encontra nesta obra: o corpo invisível, subalterno, disciplinado, imobilizado, envelhecido, refletido, violento, degradado, erotizado e liberado. Tal amplitude de abordagens ao corpo/corpos conduz discussões nos âmbitos teórico-crítico, filosófico, estético, histórico e literário com o foco em temas, entre outros: corpo e bio-política, corpo e ambiente, corpo e escatologia, corpo e espiritualidade, corpo e espaço, corpo migrante, corpo gendrado e racializado, corpo transgênero, corpo prostético, corpo monstruoso, corpo híbrido, corpo torturado, corpo político, corpo mutilado.

Nesta dimensão, vale pensar acerca de tendências teóricas contemporâneas, qualificadas como anti-humanistas e pós-antropocêntricas, como se encontra na concepção de "corpo sem órgãos", em Anti-Édipo (1972/2011) e em Mil platôs (1980/1995), de Deleuze e Guattari; de "corpo nômade", em Nomadic Subjects (1994), de Rosi Braidotti; de "corpo disciplinado", em “Os corpos dóceis', de Vigiar e punir (1975/1999), de Michel Foucault; do "corpo volátil", em Volatile bodies (1994), de Elizabeth Grosz, cujo primeiro capítulo é traduzido como "Corpos reconfigurados"; do "corpo colonizado" em Black Skin, White Masks (1967/2008), de Frantz Fanon, além das pesquisas de Sandra Gilbert, Susan Gubar (2000) e Elaine Showlater (2009), que expõem o "corpo histérico" e de Judith Butler, que, além do conceito/processo da performatividade, nos apre- senta e questiona quais os "corpos que importam", em Bodies that Matter (1993).

Estas inclinações teóricas se localizam em um espaço discursivo caracterizado como pós-colonialismo e, em certa medida, se aproximam porque são atravessadas pelo processo de contestação a regimes de conhecimento e estruturas de poder que favorecem apenas as classes dominantes. Nota-se um esforço comum às teóricas e aos teóricos referidos nesta "Introdução", no sentido de explorarem inovações a respeito do corpo. Para Braidotti, é essencial entender que, mais importante do que conceitos, quando a questão é o corpo, é a noção de processo. Vivemos, diz ela, um tempo de "ondas espasmódicas de mudança, que engendram a ocorrência simultânea de efeitos contraditórios". As mudanças tornam-se mais explícitas e eficientes devido ao vínculo que mantêm com a teoria feminista, porque esta apresenta um modelo significativo para a renovação do nosso modo de pensar acerca do ser humano e das suas estruturas incorporadas por e incrustadas em mulheres e homens, ensina Braidotti.

São variados os estudos de Rosi Braidotti acerca do corpo em sua relação com o feminino. Para ela, por exemplo, o eu corporificado, a sexualidade, a memória e a imaginação são cruciais para que a subjetividade política surja. A corporeidade ilumina e transforma nosso entendimento de nós mesmas e do mundo. $\mathrm{O}$ conhecimento feminista é um processo interativo que traz à tona aspectos da nossa existência, especialmente nossas implicações com o poder que não havíamos notado anteriormente. Ele nos desterritorializa, provoca o estranhamento em nós, afasta-nos do familiar, do íntimo, do conhecido e lança uma luz externa sobre o que é estranho. A noção de "feminino" no viés da diferença sexual não é uma entidade essencializadora; é um projeto político que visa transcender a posição tradicional do sujeito de Mulher como o Outro do Mesmo, a fim de expressá-la como o outro múltiplo do Outro, nos termos da teórica.

Tal multiplicidade de abordagens ao corpo é notada no conjunto de artigos que compõem o presente número temático da Ilha do Desterro: "Corpo e Literatura/ Body and Literature". Nessa dimensão, será possível seguir: Liane Schneider e o sujeito migrante, em Algum lugar (2009), de Paloma Vidal; Jorge Alves Santana e os processos de subjetivação, em Um copo de cólera, de 
Raduan Nassar; Maria Alice Ribeiro Gabriel e o corpo além de sua materialidade, em "O homem que fora consumido", de Edgar Allan Poe; Avital Gad Cykman e a relação entre a corporalidade e a contextualidade, em "Margaret Atwood's Bodily harm"; Deborah Scheidt e o corpo feminino, em "Barbara Baynton's 'Squeaker's mate'"; Renata Lucena Dalmaso e o corpo como metáfora visual, em "Sarah Leavitt's Tangles"; Cristina Stevens e o corpo da mãe, em "Contemporary black women narratives"; Leila Harris e Raquel Gonçalves Pires e o corpo no espaço queer caribenho, em "Valmiki's Daughter", de Shani Mootoo; Pi-hua Ni e o perigo do corpo, em "Toni Morrison's Sula”; Mélanie Grué e a celebração do corpo lésbico na obra da autora queer Dorothy Allison.

O tema proposto e tão bem realizado nestes artigos revela a sua complexidade e demonstra de que forma o corpo é considerado um desafio intrincado não só para as/os acadêmicas/os, mas para os seres humanos em sua vida diária. Na esfera representacional, ou seja, quando o foco é o texto literário, ao qual são aplicados os conhecimentos teóricos, o resultado é significativamente positivo, na medida em que demonstra não só a relevância da pesquisa como processo, acúmulo de conhecimento, adequação entre teoria e prática, mas especialmente, da busca constante e sempre atual pela significação e os sentidos do corpo.

\section{Referências}

AGOSTINHO, S. A cidade de Deus. 4. ed. Tradução: J. Dias Pereira. Lisboa: Editora Calouste Gulbenkian, 2011.

BORDO, Susan R. The flight to objectivity. Albany: State University of New York Press, 1987.

BRAIDOTTI, Rosi. "Between the no longer and the not yet: nomadic variations on the body". No site http://women. it/cyberarchive/files/braidotti.htm, consultado em: 15 ago. 2015.

Nomadic subjects: embodiment and sexual difference in contemporary feminist theory. New York: Columbia University Press, 1994.

BRAUNSTEIN, Florence e PÉPIN, Jan-François. O lugar do corpo na cultura ocidental. Trad. de João Duarte Silva. Lisboa: Artes Gráficas, s./d. [1ª ed. 1999].

BUTLER, Judith. Bodies that matter: on the discursive limits of "sex". New York: Routledge,1993.
DESCARTES, René. Discurso do método.Tradução de Paulo Neves. Porto Alegre: L\&PM, 2005.

Meditações metafísicas. Tradução de Homero Santiago e Maria Ermantina de Almeida Prado Galvão. São Paulo: Martins Fontes, 2011.

DELEUZE, Gilles e GUATTARI, Félix. O anti-Édipo: capitalismo e esquizofrenia v.1. Trad. de Luiz B. L. Orlandi. Rio de Janeiro: Ed. 34, 2011. [1ª ed. 1972, França].

Mil platôs. Trad. de Aurélio Guerra Neto e Célia Pinto Costa. Rio de Janeiro: Ed. 34, 1995. [1ª. Ed. 1980, França].

EAGLETON, Terry. A ideologia da estética. Tradução de Mauro Sá Rego Costa. Rio de Janeiro: Jorge Zahar Editor, 1990 .

FANON, Frantz. Pele negra, máscaras brancas. Tradução de Renato da Silveira. Salvador: EDUFBA, 2008. No site unegro.org.br/arquivos/arquivo_5043.pdf, consultado em 10 ag. 2015.

FREUD, Sigmund. Três ensaios sobre a teoria da sexualidade. Tradução de Jayme Salomão. Rio de Janeiro: Imago, 1976.

FOUCAULT, Michel. História da sexualidade, vol.1. Trad. Maria Thereza da Costa Albuqeurque e J. A. Guilhon Albuquerque. São Paulo: Edições Graal, 2007.

.Vigiar e Punir: nascimento da prisão. Trad. de Raquel Ramalhete. Petrópolis: Vozes, 1999. [1ª ed. 1975, França]

GILBERT, Sandra M. \& GUBAR, Susan. The madwoman in the attic: the woman writer and the nineteenthcentury literary imagination. New Haven and London: Yale University Press, 2000.

GROSZ, Elizabeth. Volatile Bodies: Toward a corporeal feminism (Theories of representation and difference). Bloomington: Indiana Universit Press, 1994

HABER, Stéphane et al. Cuerpos dominados, cuerpos en ruptura. Buenos Aires: Nueva Visión, 2007.

HUSSERL, Edmund. Ideias para uma fenomenologia pura. Tradução de Márcio Suzuki.São Paulo: Editora Ideias e Letras, 2008.

MERLEAU-PONTY, Maurice. Fenomenologia da percepção. 2. ed. Tradução: Carlos Alberto Ribeiro de Moura. São Paulo: Livraria Martins Fontes Editora Ltda., 1999.

PLATÃO. Crátilo. Tradução de Celso de Oliveira Viana. São Paulo: Paulus, 2014.

Timeus. Tradução de Rodolfo Lopes. $1^{a}$ Ed. Coimbra: Centro de Estudos Clássicos e Humanísticos, 2011. Disponível no site http://charlezine.com.br/wpcontent/uploads/2012/10/Timeu-e-Cr\%C3\%ADtiasPlat\%C3\%A3o.pdf. Acessado em 5 de setembro de 2015. 
XAVIER, Elódia. Que corpo é esse? O corpo no imaginário feminino. Florianópolis: Editora Mulheres, 2007.

SHOWALTER, Elaine. A literature of their own: British women writers, from Charlotte Brontë to Doris Lessing. London: Virago, 2009.

The female malady: women, madness, and English culture, 1830-1980. New York: Penguin Books, 1987. 